"This is the peer reviewed version of the following article: Santos D, Coelho T, Alves-Ferreira M, Sequeiros J, Mendonça D, Alonso I, Sousa A, Lemos C. Large normal alleles of ATXN2 decrease age at onset in transthyretin familial amyloid polyneuropathy Val30Met patients. Ann Neurol. 2019 Feb;85(2):251-258. doi: 10.1002/ana.25409, which has been published in final form at https://onlinelibrary.wiley.com/doi/full/10.1002/ana.25409. This article may be used for non-commercial purposes in accordance with Wiley Terms and Conditions for Use of Self-Archived Versions."

\title{
Large Normal Alleles of ATXN2Decrease Age at Onset in Transthyretin Familial Amyloid Polyneuropathy Val30Met Patients
}

Diana Santos, PhD, 1,2,3 Teresa Coelho, MD, ${ }^{4}$ Miguel Alves-Ferreira, MSc, ${ }^{1,2,3}$ Jorge Sequeiros, MD, PhD, 1,2,3 Denisa Mendonça, $\mathrm{PhD},{ }^{3,5}$ Isabel Alonso, $\mathrm{PhD}, 1,2,3$ Alda Sousa, $\mathrm{PhD},{ }^{1,2,3}$ and Carolina Lemos, $\mathrm{PhD}^{1,2,3}$ 


\title{
Large Normal Alleles of ATXN2 Decrease Age at Onset in Transthyretin Familial Amyloid Polyneuropathy Val30Met Patients
}

\author{
Diana Santos, $\mathrm{PhD}, 1,2,3$ Teresa Coelho, MD, 4 Miguel Alves-Ferreira, MSc, ${ }^{1,2,3}$ \\ Jorge Sequeiros, MD, PhD, ${ }^{1,2,3}$ Denisa Mendonça, $\mathrm{PhD},{ }^{3,5}$ Isabel Alonso, $\mathrm{PhD}, 1,2,3$ \\ Alda Sousa, $\mathrm{PhD},{ }^{1,2,3}$ and Carolina Lemos, $\mathrm{PhD}^{1,2,3}$
}

\begin{abstract}
Objective: Transthyretin (TTR)-related familial amyloid polyneuropathy (FAP) is an autosomal dominant neurological disease, caused most frequently by a Val30Met (now classified as Val50Met) substitution in TTR. Age at onset (AO) ranges from 19 to 82 years, and variability exists mostly between generations. Unstable oligonucleotide repeats in various genes are the mechanism behind several neurological diseases, found also to act as modifiers for other disor- ders. Our aim was to investigate whether large normal repeat alleles of 10 genes had a possible modifier effect in $A O$ in Portuguese TTR-FAP Val30Met families.

Methods: We analyzed 329 Portuguese patients from 123 families. Repeat length (at ATXN1, ATXN2, ATXN3, ATXN7, $T B P, A T N 1, H T T, J P H 3, A R$, and DMPK) was assessed by single and multiplex polymerase chain reaction, using fluorescently labeled primers, followed by capillary electrophoresis. We used a family-centered approach, and generalized estimating equations were used to account for $\mathrm{AO}$ correlation between family members.

Results: For $A T X N 2$, the presence of at least 1 allele longer than 22 CAGs was significantly associated with an earlier onset in TTR-FAP Val30Met, decreasing mean AO by 6 years ( $95 \%$ confidence interval $=-8.81$ to $-2.19, p=0.001)$. No association was found for the remaining repeat loci.

Interpretation: Length of normal repeats at ATXN2 may modify AO in TTR-FAP Val30Met and may function as a risk factor. This can be due to the role of $A T X N 2$ in RNA metabolism and as a modulator of various cellular processes, including mitochondrial stress. This may have relevant implications for prognosis and the follow-up of presymptomatic carriers.
\end{abstract}

ANN NEUROL 201 9;85:251-258

\section{$\mathrm{T}$}

ransthyretin (TTR)-related familial amyloid polyneuro- pathy (FAP) is an autosomal dominant systemic amyloid- osis characterized by extracellular amyloid deposits, and it is caused by a point variant in the TTR gene (chr18q12.1; OMIM 176300). Although $>100$ variants have already been identified, Val50Met (classically known as Val30Met, NM_000371.3) is the most frequently described diseasecausing variant in this gene, associated with large clusters. $^{1}$
TTR-FAP was initially described in Portugal, by Andrade, as a disease with age at onset (AO) mostly between 25 and 35 years. ${ }^{2}$ Nowadays, in Portuguese fami- lies, TTR-FAP Val30Met shows a wide variation in AO (19-82 years). ${ }^{3}$ Furthermore, it was found that early onset $(\mathrm{AO}<40$ years $)$ and late onset $(\mathrm{AO} \geq 50$ years) cases, and even asymptomatic carriers aged 95 years, may coexist in the same family, ${ }^{4,5}$ where offspring often show an earlier

View this article online at wileyonlinelibrary.com. DOI: 10.1002/ana.25409

Received Jul 13, 2018, and in revised form Jan 4, 2019. Accepted for publication Jan 4, 2019.

Address correspondence to

Dr Lemos, Universidade do Porto, Rua Alfredo Allen, n 208, 4200-135 Porto, Portugal. Email: clclemos@ibmc.up.pt

From the ${ }^{1} \mathrm{i} 3 \mathrm{~S}$, Instituto de Investigação e Inovação em Saúde, Universidade do Porto; ${ }^{2}$ UnIGENe, IBMC, Institute for Molecular and Cell Biology, Universidade do Porto; ${ }^{3}$ ICBAS, Instituto de Ciências Biomédicas Abel Salazar, Universidade do Porto; ${ }^{4}$ UCA, Unidade Corino de Andrade, Centro Hospitalar do Porto (CHP); and ${ }^{5}$ ISPUP, Instituto de Saúde Pública, Universidade do Porto, Porto, Portugal

Additional supporting information can be found in the online version of this article. 
AO than their affected parent (anticipation). Recently, Lemos et al showed that anticipation was a real biological phenomenon still lacking explanation. ${ }^{3}$

Since 1991, a new molecular mechanism responsible for several neurogenetic disorders was found, legitimizing anticipation in several diseases such as myotonic dystrophy type 1 (DM1). ${ }^{6}$

More recently, the role of expanded repetitive tracts as genetic modifiers of other genetic diseases has been evi- denced. Previous studies showed that an intermediate- length $(\mathrm{CAG})_{\mathrm{n}}$ expansion in the coding region of the ataxin-2 (ATXN2) gene, responsible for spinocerebellar ataxia type 2 (SCA2), was a major contributor to amyo- trophic lateral sclerosis (ALS). ${ }^{7-9}$

Additionally, other authors found that the normal repeat length in other spinocerebellar ataxia (SCA) genes also modulated AO of different SCAs. ${ }^{10-12}$ Repeat size in the ATXN2, atrophin 1 (ATN1), and huntingtin (HTT) genes, interacting with $A T X N 3$, may modulate $\mathrm{AO}$ in Machado-Joseph disease (MJD/SCA3).$^{10}$ These results, however, were not replicated in an Azorean cohort. ${ }^{13}$

$H T T$, TATA-box binding protein $(T B P)$, and ATXN7 are directly involved in transcription and transcriptional regulation, ${ }^{14-19}$ whereas ATXNI and ATXN2 may interfere with RNA metabolism. ${ }^{20,21}$ In DM1, repeat expansions may affect splicing of the same target RNAs. ${ }^{22}$ Variants in andro- gen receptor $(A R)$ are associated with variable AO in TTR- FAP Val30Met in both men and women. ${ }^{23}$

Recently, some studies have focused on possible modifier genes of AO in TTR-FAP Val30Met, using case-control ${ }^{24,25}$ and family-centered approaches ${ }^{23,26}$; however, the role of repeat loci has not yet been explored. To the best of our knowledge, only 1 study

has looked for triplet repeat expansions as a possible explanation for anticipation in TTR-FAP Val30Met; however, only a small sample of 9 Portuguese affected parent-offspring pairs with large anticipation $(>12$ years) and 19 noncarrier indi- viduals were compared, no major differences being found. ${ }^{27}$ We now focused on $\mathrm{AO}$ variability, applying more recent technologies for accurate and reproducible determi- nation of repeat length of normal repeats in 10 genes related to neurodegenerative disorders, using a family- centered approach. We tested the hypothesis that larger normal alleles in these genes are more prone to be associ- ated with an earlier onset of TTR-FAP Val30Met than smaller normal alleles.

\section{Subjects and Methods}

\section{Patients}

At the Unidade Corino de Andrade - Centro Hospitalar do Porto (CHP; Porto, Portugal), the largest TTR-FAP Val30Met patient's reg- istry worldwide has been collected and clinically characterized over the past 75 years. We retrieved a total of 329 patients with known AO. These patients belonged to 123 different families with at least 2 gen- erations affected, coming from various geographical areas of the

country. For each patient, AO was established by the same

team of neurologists specializing in TTR-FAP Val30Met; AO was defined as the appearance of first symptoms (usually

sensorial loss or autonomic dysfunction), reported by the patient and coinciding with an abnor- mal neurological and/or neurophysiological examination. In the smaller number of cases where cardiac or kidney involvement is the

sole symptom, its manifestation also defines onset of the disease.

\section{Distribution of Normal Alleles in Noncarriers of Val30Met Variant}

To assess, for each candidate gene, the distribution of normal repeat length, we analyzed 70 healthy persons (140 alleles), spouses and unaffected siblings from the same families, molecu- larly confirmed as noncarriers of the Val30Met variant. They had the same geographical origin and were matched by family to our patients, but did not bear the Val30Met mutation.

\section{Sample Collection and Storage}

DNA samples were collected at CHP and stored at the Predictive and Preventive Genetics Center, Institute for Molecular and Cell Biology, Instituto de Investigação e Inovação em Saúde, a bio- bank authorized by the National Commission for Data Protec- tion to collect and store diagnostic and research samples and associated data. Written informed consent was obtained for all participants. The CHP's ethics committee approved the study.

\section{DNA Analyses}

Genomic DNA was extracted from peripheral blood leukocytes, using the standard salting-out method, ${ }^{28}$ or from saliva, using ORAGENE kits, according to the manufacturer's instructions (DNA Genotek, Kanata, ON, Canada). DNA samples were quantified in a NanoDrop spectrophotometer.

\section{Repeat Selection and Genotyping}

A set of 10 candidate genes that show CAG/CTG trinucleotide repeat expansions associated with different neurological disorders were selected to explore the impact of repeat size at these loci on AO of TTR-FAP Val30Met (Table 1).

Repeat length was determined by a polymerase chain reac- tion (PCR) amplification assay, using fluorescently labeled for- ward primers. Sequences for PCR primers were designed with Primer3Plus software, and the presence of hairpins and second- ary structures was ascertained with AutoDimer v1.0 (primer sequences available upon request).

To amplify the set of 10 short tandem repeats, single-plex PCR amplifications were performed in a final volume of

$10.94 \mu \mathrm{l}$ for $H T T$ and $12.50 \mu \mathrm{l}$ for ATXN2, ATXN7, TBP, and myotonic dystrophy protein kinase $(D M P K)$, using $6.25 \mu \mathrm{l}$ of HotStar Taq Master Mix Kit (Qiagen, Hilden, Germany). In each PCR reaction, primer concentration was $0.71 \mu \mathrm{M}, 0.8$ $\mu \mathrm{M}, 1 \mu \mathrm{M}, 0.4 \mu \mathrm{M}$, and $0.24 \mu \mathrm{M}$, respectively. All reactions used

$1.25 \mu \mathrm{l}$ of dimethylsulfoxide (10\%), except for TBP gene, and $20 \mathrm{ng}$ of DNA. Cycling conditions are available upon request. 

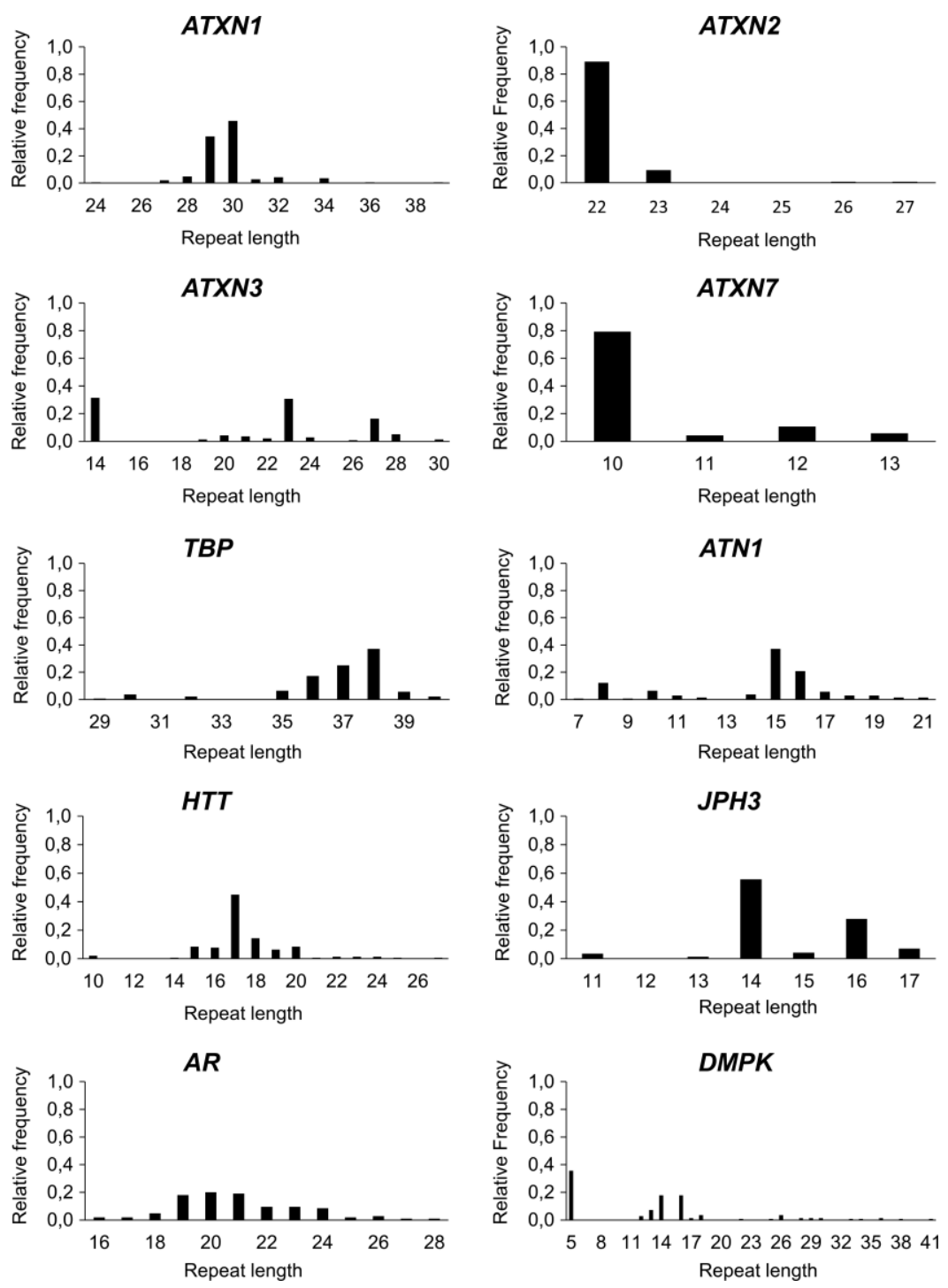

FIGURE 1: Repeat length distribution of the 10 genes studied in our sample of 70 noncarriers of Val30Met.

Then, 2 multiplex PCR reactions were carried out (one multiplex 1 for $A T X N 1, A T N 1$ and junctophilin 3 [JPH3] and the other multiplex 2 for $A T X N 3$ and $A R$ ), in a final volume of $12.50 \mu \mathrm{l}$, using $6.25 \mu \mathrm{l}$ of Multiplex PCR Master Mix (Qiagen). Primer concentration for multiplex 1 was $0.5 \mu \mathrm{M}, 0.25 \mu \mathrm{M}$, and $0.6 \mu \mathrm{M}$, respectively, and for multiplex 2 it was $0.62 \mu \mathrm{M}$ for all primers and $20 \mathrm{ng}$ of DNA. PCR products were mixed with the Liz-500 size standard (Applied Biosystems, Foster City, CA). Size of fragments was determined by capillary electrophoresis using the ABI-PRISM 3130 XL Genetic Analyzer (Applied Biosystems) and analyzed with GeneMapper v4.0 software (Applied Biosystems). Automated DNA sequencing of representative alleles from each locus in the reverse direction using Big Dye Terminator Cycle Sequencing v1.1, Ready Reaction (Applied Biosystems), according to the manufacturer's instructions, was performed to determine the exact correspondence between fragment size and repetitive tract length.

\section{Classification of Allele Size according to the Number of CAG/CTG Repeats}

For ATXN1, ATXN2, ATXN3, ATXN7, HTT, and DMPK, we classified normal alleles as short, medium, intermediate-short, and intermediate-large according to the classification of Tezenas du Montcel et $\mathrm{al}^{10}$ or the criteria of Gene Reviews ${ }^{29}$ (Table 2).

For $T B P, J P H 3$, and $A R$ loci, there is no description of intermediate alleles; also, there were none found in our population for ATN1. Therefore, we considered a different approach for their analysis (see the Design and Statistical Analy- sis section); alleles were classified as short if their size was equal to or smaller than the median and large if they were larger than the median.

\section{Design and Statistical Analysis}

For ATXN1, ATXN2, ATXN3, ATXN7, HTT, and DMPK, genotypes were divided into 2 categories: (1) both alleles were of short or medium length and (2) there was at least 1 intermediate 


\begin{tabular}{|c|c|c|c|}
\hline Gene & $\begin{array}{l}\text { Chr } \\
\text { Location }\end{array}$ & Repetitive Motif & Disease \\
\hline ATXN1 (ataxin-1) & $6 \mathrm{p} 22.3$ & $(\mathrm{CAG})_{\mathrm{n}}(\mathrm{CAT})_{\mathrm{n}}(\mathrm{CAG})_{\mathrm{n}}$ & Spinocerebellar ataxia type 1 \\
\hline ATXN2 (ataxin-2) & $12 q 24.1$ & $\left([\mathrm{CAG}]_{\mathrm{n}} \mathrm{CAA}[\mathrm{CAG}]_{\mathrm{n}}\right)_{\mathrm{n}}$ & Spinocerebellar ataxia type 2 \\
\hline ATXN3 (ataxin-3) & $14 \mathrm{q} 21$ & $\begin{array}{l}(\mathrm{CAG})_{2} \text { CAA AAG CAG CAA } \\
(\mathrm{CAG})_{\mathrm{n}}\end{array}$ & Machado-Joseph disease \\
\hline$A T X N 7$ (ataxin-7) & $3 \mathrm{p} 21.1-\mathrm{p} 12$ & $(\mathrm{CAG})_{\mathrm{n}}$ & Spinocerebellar ataxia type 7 \\
\hline$T B P$ (TATA-box binding protein) & $6 q 27$ & $(\mathrm{CAG})_{\mathrm{n}}(\mathrm{CAA})_{\mathrm{n}}(\mathrm{CAG})_{\mathrm{n}}$ & Spinocerebellar ataxia type 17 \\
\hline ATN1 (atrophin 1) & $12 \mathrm{p} 13.31$ & $(\mathrm{CAG})_{\mathrm{n}}$ & $\begin{array}{l}\text { Dentatorubral-pallidoluysian } \\
\text { atrophy }\end{array}$ \\
\hline HTT (huntingtin) & $4 p 16.3$ & $(\mathrm{CAG})_{\mathrm{n}}$ & Huntington disease \\
\hline JPH3 (junctophilin 3) & $16 \mathrm{q} 24.3$ & $(\mathrm{CTG})_{\mathrm{n}}$ & $\begin{array}{l}\text { Huntington disease-like type } \\
2\end{array}$ \\
\hline$A R$ (androgen receptor) & $\mathrm{Xq} 12$ & $(\mathrm{CAG})_{\mathrm{n}}$ & $\begin{array}{l}\text { Spinal and bulbar muscular } \\
\text { atrophy }\end{array}$ \\
\hline $\begin{array}{l}D M P K \text { (myotonic dystrophy protein } \\
\text { kinase) }\end{array}$ & $19 q 13.3$ & $(\mathrm{CTG})_{\mathrm{n}}$ & Myotonic dystrophy type 1 \\
\hline aromosome. & & & \\
\hline
\end{tabular}

allele. For $T B P, J P H 3, A T N 1$, and $A R$, we divided genotypes into 3 categories: (1) both alleles were equal to or smaller than the median, (2) at least 1 was larger than the median, and (3) both alleles were larger than the median.

For each locus, genotypes where both alleles were of short/medium length or equal to or smaller than the median were considered as the reference and compared to all genotypes including at least 1 intermediate allele.

Our family-centered approach means that we included in the analysis several members of the same family, where each patient was "nested" in his/her family. To account for nonindependency of AO between members of the same family, we used generalized

\begin{tabular}{|c|c|c|c|c|}
\hline \multirow[b]{3}{*}{ Genes } & \multicolumn{2}{|c|}{ Normal Alleles } & \multicolumn{2}{|l|}{ Intermediate Alleles } \\
\hline & Short & Medium & Intermediate-Short & Intermediate-Large \\
\hline & $<36$ & - & - & $36-38$, pure repeat \\
\hline ATXN2 & $<22$ & 22 & $23-26$ & $27-29$ \\
\hline ATXN3 & $<16$ & $16-24$ & - & $25-37$ \\
\hline ATXN7 & $<10$ & $10-11$ & - & $12-15$ \\
\hline$T B P$ & - & - & - & - \\
\hline$H T T$ & $\leq 26$ & - & - & $27-35$ \\
\hline JPH3 & - & - & - & - \\
\hline ATN1 & $<37$ & - & - & $37-48$ \\
\hline$A R$ & - & - & - & - \\
\hline$D M P K$ & $\leq 37$ & - & - & $38-50$ \\
\hline
\end{tabular}


estimating equations (GEEs), by performing a weighted analysis adjusted for gender. ${ }^{30}$ Therefore, we assessed whether there was asso- ciation of the length of the various repeats with $\mathrm{AO}$ (as the depen- dent variable). The unstandardized coefficient $(B)$ corresponds to the mean AOvariation observed in the individuals carrying a specific genotype when compared with the reference category. To correct for multiple testing, we applied a Bonferroni correction ( $\alpha$ was set at

0.005 in the GEE analysis, as we tested 10 genes).

We also analyzed parent-offspring transmissions, assessing whether larger alleles were more likely to be transmitted by the affected father or by the affected mother, using a Fisher exact test. All statistical analyses were performed with SPSS Statistics v23 (IBM, Armonk, NY). A $p$ value $<0.05$ was considered statis- tically significant.

\section{Results}

We assessed the length of repeats at both alleles of a set of 10 loci in a sample of 329 Portuguese patients and in 70 of their noncarrier relatives. To search for potential modifier effects of the repetitive motif length on AO varia- tion, we analyzed a sample of 329 TTR-FAP Val30Met patients belonging to 123 different families with a mean $\mathrm{AO}$ of $39.83 \mathbf{T} 13.21$ years (range $=53$ years). Mean AO in males (38.09 $\mathbf{T} 13.96$ years, range $=$ 51 years) was lower than in female patients (41.39 12.33 years, range $=53$ years), as described in the literature, ${ }^{3,4,23}$ and this difference was statistically significant $(95 \%$ confidence interval $[\mathrm{CI}]=-6.17$ to $-0.43, p=0.024)$.

\section{Distribution of Repeat Lengths in the Sample of Noncarriers of Val30Met}

Table 3 describes the range of normal alleles for each gene, as established in the literature and the range found in our sam- ple, the median, and interquartile range. The Figure 1 shows the distribution of those repeat lengths in our sample.

This sample is very much like those in other countries, if we consider error margins for normal CAGs, ${ }^{10,11}$ as well as in previous studies in the Portuguese population for Huntington disease ${ }^{13,31}$; MJD/SCA $3^{13,32,33}$; SCA1, SCA2, SCA7, and dentatorubral pallidoluysian atrophy ${ }^{13,33}$; and $\mathrm{SCA} 17,{ }^{33}$ in terms of both range and allele frequencies.

\section{Analysis of Repeat Length and AO Variation}

No significant association with AO in TTR-FAP Val30Met patients was seen for repeat length in $A T X N 1$, ATXN3, ATXN7, TBP, ATN1, HTT, JPH3, AR, and $D M P K$ (Supplementary Table 1).

\section{ATXN2 (CAG) with $>22$ Alleles Is Associated with an Earlier Onset in TTR-FAP Val3OMet Patients}

Normal CAG repeats in ATXN2 may range from 14 to

31 repeats (see Table 3 ). In our sample, the normal

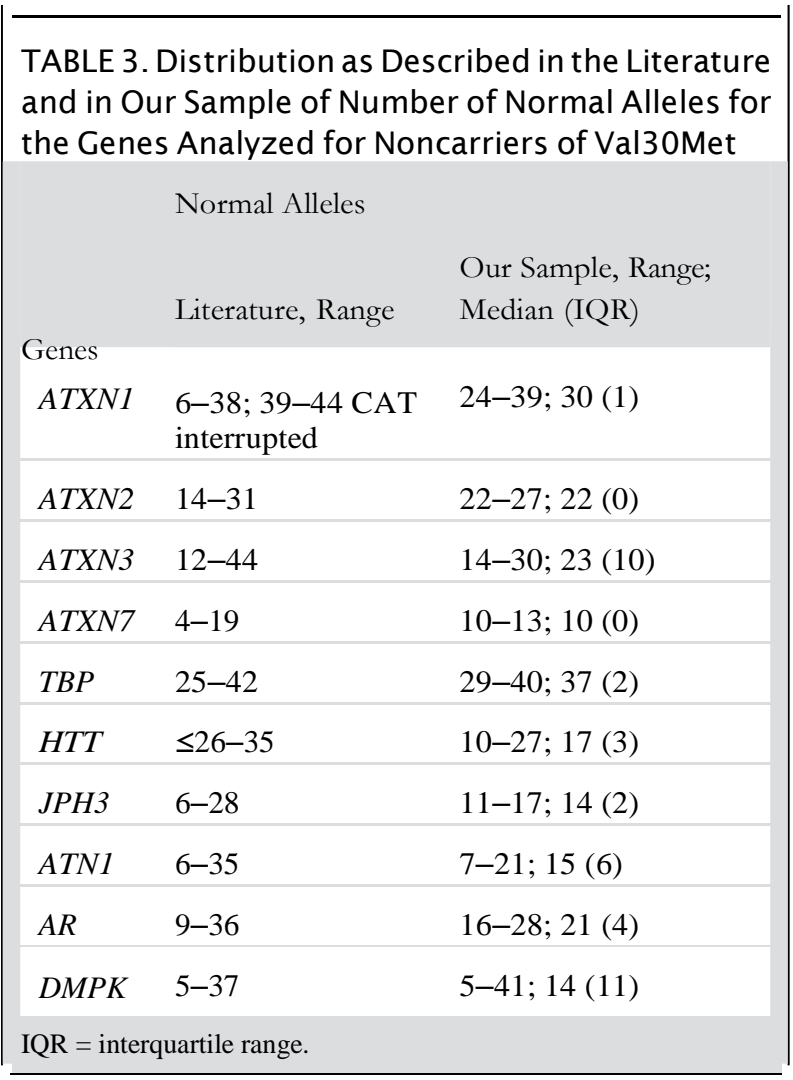

ATXN2 $(\mathrm{CAG})_{\mathrm{n}}$ alleles were less polymorphic, displaying only 6 different sizes, ranging from 22 to 27 repeats (see Table 3$)$. The $(\mathrm{CAG})_{22}$ allele was the most frequent $(88 \%)$, followed by $(\mathrm{CAG})_{23}(9 \%$; see Fig 1$)$, as seen in other populations.

The homozygous genotype for $22 \mathrm{CAG}$ repeats $(n=261)$ was considered the reference category against which all other genotypes $(n=68$ patients), where at least

1 allele with $>22$ CAGs was present, were compared. Mean AO of the 261 TTR-FAP Val30Met patients homozygous for $(\mathrm{CAG})_{22}$ was $40.92 \mathbf{T} 13.55$ years (range $=53$ years), whereas mean $\mathrm{AO}$ of the 68 patients carrying at least 1 allele longer than 22 CAGs was $35.63+0.93$ years (range $=50$ years), and this difference was statistically significant $(95 \% \mathrm{CI}=1.79$ to 8.78 , $p=0.003)$. For the reference category, mean $\mathrm{AO}$ was

$38.92 \mathbf{T} 14.12$ years in males and $42.81 \mathbf{T} 12.75$ years in females. This difference was statistically signi cant $(95 \%$ $\mathrm{CI}=-7.18$ to $-0.61, p=0.020)$.

In the group carrying at least 1 allele longer than 22 CAGs, mean AO was 34.45 T 12.82 years in males and $36.51 \mathbf{T} 9.35$ years in females. However, this differ- ence was not statistically significant $(95 \% \mathrm{CI}=$ -7.72 to $3.59, p=0.466)$.

Using a family-centered approach, we found that patients carrying at least 1 ATXN2 allele larger than 22 repeats had an earlier mean onset (almost 6 years; $95 \%$ 
$\mathrm{CI}=-8.81$ to $-2.19, p=0.001)$ after adjusting for $\operatorname{sex}$ (Supplementary Table 2). This effect was not sexdependent and remained significant after adjustment for multiple comparisons, using the conservative Bonferroni correction $(p=0.005)$. When we analyzed the relationship between gender of transmitting (affected) parent and size of the alleles, we found that large normal alleles were equally transmitted from the mother or the father $(p=0.698)$. Analysis of transmissions was only performed for the ATXN2 gene, as it was the only one where larger alleles showed a significant association with AO.

\section{Discussion}

Several genetic modifiers of AO in TTR-FAP Val30Met have already been identified, ${ }^{23-26}$ but the possible role of large normal alleles in genes containing a repeat motif had never been considered and deserved particular attention. With this in mind, our strategy was to assess whether the normal CAG/CTG repeat length in 10 genes could act as a genetic modifier influencing the AO of TTR-FAP Val30Met patients.

Large normal ATXN2 alleles showed a strong associ- ation with AO, patients carrying at least 1 normal allele with $>22$ repeats in ATXN2 being prone to earlier onset.

Previous studies have shown that length of normal CAG repeats in ATXN2 is quite variable (1431 CAGs), depending on the population, with 22 and $23 \mathrm{CAG}$ repeats being the most common alleles, ${ }^{34,35}$ similarly to what was found in our sample, where its range was 22 to

28. The CAG repeat in $A T X N 2$ is responsible for SCA2 when its length is $>32$ to 34 units, correlating with $\mathrm{AO}$ and severity. ${ }^{36,37}$ Some SCA2 patients with 32 to 33 repeats show later onset. ${ }^{38,39}$ Moreover, previous studies have suggested that intermediate-length $\mathrm{CAG}$ repeats in ATXN2 (27-33 units) are associated with increased risk for some diseases and modulate $\mathrm{AO}$ in $\mathrm{ALS}^{7,8,40}$ and Par- kinson disease (PD), ${ }^{41}$ but seemingly not for hereditary spastic paraplegias. ${ }^{42}$ Intermediate repeat expansions in ATXN2 associate with PD in Asian populations, ${ }^{43,44}$ indi- cating that different genetic background may play a role.

Ataxin-2 is one of the polyQ proteins, highly expressed in various neuronal and non-neuronal tissues, including the brain, ${ }^{45}$ and has been involved in the regulation of several biological processes such as RNAmediated metabolism, translation regulation, cytoskeleton reorgani- zation, $\mathrm{Ca}^{2+}$ homeostasis, and mitochondrial stress. ${ }^{46}$ The hallmark of TTR-FAP Val30Met is the presence of extra- cellular deposits of TTR aggregates and amyloid fibrils in several tissues; particularly, in peripheral nerves, diverse molecular pathways associated with degeneration have been confirmed using in vivo samples and cell culture studies, including activation of nuclear factor $\mathrm{kB}$, proinflammatory cytokines, oxidative stress, and endoplas- mic reticulum (ER) stress. ${ }^{47}$ Oxidative stress may be further increased by the presence of (CAG) $23-28$ alleles at the ATXN2 locus and contribute to the processing of mis- folded proteins, which in turn cause ER stress with enhanced reactive oxygen species production, thereby cre- ating a feedback loop. ${ }^{48}$

Another interesting feature is that when ATXN2 interacts with ALS pathogenic pathways, an altered locali- zation of ATXN2 has been observed. ${ }^{7}$ These altered mech- anisms can lead to an early AO, because $A T X N 2$ intermediate-length repeats can alter protein stability or degradation affecting ataxin-2 levels, which may promote interaction with other proteins. ${ }^{7}$ In ALS, it was also found that $A T X N 2$ intermediate alleles modulate disease path- ways via its RNA-dependent interaction with other ALS- related proteins, such as FUS and TDP43. ${ }^{49}$ Another study found that coexpression of ATXN2 intermediate allele, combined with C9orf72 depletion, increases ataxin- 2 aggregation, leading to neuronal toxicity. ${ }^{50}$ Therefore, it would be interesting to assess ataxin-2 interaction with other TTR-FAP Val30Metassociated proteins.

To confirm these hypotheses, future studies focused on level of protein expression with $(\mathrm{CAG})_{23-28}$ are needed. Our results lead to the hypothesis that (CAG) ${ }_{23-28}$ in ATXN2 might influence TTR aggregation and amyloid fibril formation, contributing as a risk factor for neurodegeneration. Furthermore, they may also indicate that a population-specific genetic profile at ATXN2 influences the ability to confirm/discard the potential modifier effect in AO variation; for this reason, replication studies should be performed in different populations. $^{13}$

Importantly, Tezenas du Montcel et al also found in a large cohort that repeat-encoding genes with normal length can be modulators of AO for other SCAs, confirming that these interactions may occur in different populations and disorders. ${ }^{10}$

Our findings support the hypothesis that large nor- mal alleles in ATXN2 may modulate AO in TTRFAP Val30Met. Although no significant association was found for the other genes, we cannot exclude a role for dynamic mutations other than the ones studied. We had a special concern with statistical power, taking into account (1) sam- ple size (one of the largest sample collections of TTR-FAP Val30Met available worldwide); and (2) that the statistical analysis focused on a parametric test (GEE), which is a powerful statistical method, and multiple testing correc- tions to prevent type I errors. The results obtained also reinforce the importance of replication studies in other populations to confirm these results. Unraveling factors that contribute to modulating $\mathrm{AO}$ is important for 
understanding the disease pathogenesis, for improving genetic counselling, and for the follow-up of presymptomatic carriers.

\section{Acknowledgment}

This work was supported by the Fundação para a Ciência e Tecnologia (FCT; PTDC/SAUGMG/100240/2008 and PEsT), and co-funded by ERDF, COMPETE, and Multi- annual Financing of Research Units (FCT). D.S. and M.A.-F. are the recipients of an FCT fellowship (SFRH/BD/ 91160/2012 and SFRH/BD/101352/2014, respectively).

We thank all patients for participating in this study and V. Costa for help assembling family data.

\section{Author Contributions}

All authors contributed to the conception and design of the study and the acquisition and analysis of data. D.S., A.S., and C.L. drafted a significant portion of the manuscript or figure.

\section{Potential Conflicts of Interest}

Nothing to report.

\section{References}

1. Benson MD. Pathogenesis of transthyretin amyloidosis. Amyloid 2012;19(Suppl 1):14-15.

2. Andrade C. A peculiar form of peripheral neuropathy; familiar atypical generalized amyloidosis with special involvement of the peripheral nerves. Brain 1952;75:408-427.

3. Lemos C, Coelho T, Alves-Ferreira M, et al. Overcoming artefact: anticipation in 284 Portuguese kindreds with familial amyloid polyneuropathy (FAP) ATTRV30M. J Neurol Neurosurg Psychiatry 2014; 85:326-330.

4. Sousa A, Coelho T, Barros J, Sequeiros J. Genetic epidemiology of familial amyloidotic polyneuropathy (FAP)-type I in Povoa do Varzim and Vila do Conde (north of Portugal). Am J Med Genet 1995;60: 512521.

5. Sequeiros J, Saraiva MJ. Onset in the seventh decade and lack of symptoms in heterozygotes for the TTRMet30 mutation in hereditary amyloid neuropathy-type I (Portuguese, Andrade). Am J Med Genet 1987;27:345-357.

6. Margolis RL, Mclnnis MG, Rosenblatt A, Ross CA. Trinucleotide repeat expansion and neuropsychiatric disease. Arch Gen Psychiatry 1999;56:1019-1031

7. Elden AC, Kim HJ, Hart MP, et al. Ataxin-2 intermediate-length polyglutamine expansions are associated with increased risk for ALS. Nature 2010;466:1069-1075.

8. Lee T, Li YR, Ingre C, et al. Ataxin-2 intermediate-length polyglutamine expansions in European ALS patients. Hum Mol Genet 2011; 20:1697-1700.

9. Soraru G, Clementi M, Forzan M, et al. ALS risk but not phenotype is affected by ataxin-2 intermediate length polyglutamine expansion. Neurology 2011;76:2030-2031.
10. Tezenas du Montcel S, Durr A, Bauer P, et al. Modulation of the age at onset in spinocerebellar ataxia by CAG tracts in various genes. Brain 2014;137(pt 9):2444-2455.

11. Chen $Z$, Zheng $C$, Long $Z$, et al. (CAG)n loci as genetic modifiers of age-at-onset in patients with Machado-Joseph disease from mainland China. Brain 2016;139(pt 8):e41.

12. Pulst SM, Santos N, Wang D, et al. Spinocerebellar ataxia type 2: polyQ repeat variation in the CACNA1A calcium channel modifies age of onset. Brain 2005;128(pt 10):2297-2303.

13. Raposo M, Ramos A, Bettencourt C, Lima M. Replicating studies of genetic modifiers in spinocerebellar ataxia type 3: can homogeneous cohorts aid? Brain 2015;138(pt 12):e398.

14. Dunah AW, Jeong $H$, Griffin A, et al. Sp1 and TAFII130 transcriptional activity disrupted in early Huntington's disease. Science 2002; 296:2238-2243.

15. Freiman RN, Tjian R. Neurodegeneration. A glutamine-rich trail leads to transcription factors. Science 2002;296:2149-2150.

16. van Roon-Mom WM, Reid SJ, Faull RL, Snell RG. TATA-binding protein in neurodegenerative disease. Neuroscience 2005;133:863-872.

17. Palhan VB, Chen S, Peng GH, et al. Polyglutamine-expanded ataxin7 inhibits STAGA histone acetyltransferase activity to produce retinal degeneration. Proc Natl Acad Sci U S A 2005;102:8472-8477.

18. McMahon SJ, Pray-Grant MG, Schieltz D, et al. Polyglutamineexpanded spinocerebellar ataxia-7 protein disrupts normal SAGA and SLIK histone acetyltransferase activity. Proc Natl Acad Sci U S A 2005;102:8478-8482.

19. Zhai $W$, Jeong $H$, Cui $L$, et al. In vitro analysis of huntingtin-mediated transcriptional repression reveals multiple transcription factor targets. Cell 2005;123:1241-1253.

20. Ralser M, Albrecht M, Nonhoff $U$, et al. An integrative approach to gain insights into the cellular function of human ataxin-2. J Mol Biol 2005;346:203-214.

21. Irwin S, Vandelft M, Pinchev D, et al. RNA association and nucleocytoplasmic shuttling by ataxin-1. J Cell Sci 2005;118(pt 1):233-242.

22. Cho DH, Tapscott SJ. Myotonic dystrophy: emerging mechanisms for DM1 and DM2. Biochim Biophys Acta 2007;1772:195-204.

23. Santos D, Coelho T, Alves-Ferreira M, et al. Variants in RBP4 and AR genes modulate age at onset in familial amyloid polyneuropathy (FAP ATTRV30M). Eur J Hum Genet 2016;24:756-760.

24. Soares ML, Coelho T, Sousa A, et al. Susceptibility and modifier genes in Portuguese transthyretin V30M amyloid polyneuropathy: complexity in a single-gene disease. Hum Mol Genet 2005;14: 543553.

25. Dardiotis E, Koutsou P, Zamba-Papanicolaou E, et al. Complement $\mathrm{C} 1 \mathrm{Q}$ polymorphisms modulate onset in familial amyloidotic polyneuropathy TTR Val30Met. J Neurol Sci 2009;284:158-162.

26. Santos D, Coelho T, Alves-Ferreira M, et al. Familial amyloid polyneuropathy in Portugal: new genes modulating age-at-onset. Ann Clin Transl Neurol 2017;4:98-105.

27. Soares M, Buxbaum J, Sirugo G, et al. Genetic anticipation in Portuguese kindreds with familial amyloidotic polyneuropathy is unlikely to be caused by triplet repeat expansions. Hum Genet 1999;104: 480485.

28. Miller SA, Dykes DD, Polesky HF. A simple salting out procedure for extracting DNA from human nucleated cells. Nucleic acids Res 1988; $16: 1215$.

29. Adam MP, Ardinger, HH, Pagon RA, Wallace SE. GeneReviews. Seattle, WA: University of Washington, 1993-2017.

30. Zeger SL, Liang KY. Longitudinal data analysis for discrete and continuous outcomes. Biometrics 1986;42:121-130.

31. Costa MC, Magalhaes $P$, Guimaraes $L$, et al. The CAG repeat at the Huntington disease gene in the Portuguese population: insights into 
its dynamics and to the origin of the mutation. J Hum Genet 2006; 51:189-195.

32. Lima M, Costa MC, Montiel R, et al. Population genetics of wild-type CAG repeats in the Machado-Joseph disease gene in Portugal. Hum Hered 2005;60:156-163.

33. Silveira I, Miranda C, Guimaraes L, et al. Trinucleotide repeats in 202 families with ataxia: a small expanded (CAG)n allele at the SCA17 locus. Arch Neurol 2002;59:623-629.

34. Pulst SM, Nechiporuk A, Nechiporuk T, et al. Moderate expansion of a normally biallelic trinucleotide repeat in spinocerebellar ataxia type 2. Nat Genet 1996;14:269-276.

35. Ramos EM, Martins S, Alonso I, et al. Common origin of pure and interrupted repeat expansions in spinocerebellar ataxia type 2 (SCA2). Am J Med Genet B Neuropsychiatr Genet 2010;153B: 524-531.

36. Imbert G, Saudou F, Yvert G, et al. Cloning of the gene for spinocerebellar ataxia 2 reveals a locus with high sensitivity to expanded CAG/glutamine repeats. Nat Genet 1996;14:285-291.

37. Schols L, Gispert S, Vorgerd M, et al. Spinocerebellar ataxia type 2. Genotype and phenotype in German kindreds. Arch Neurol 1997; 54:1073-1080.

38. Fernandez M, McClain ME, Martinez RA, et al. Late-onset SCA2: 33 CAG repeats are sufficient to cause disease. Neurology 2000;55: 569-572.

39. Kim JM, Hong S, Kim GP, et al. Importance of low-range CAG expansion and CAA interruption in SCA2 Parkinsonism. Arch Neurol 2007;64:1510-1518.

40. Gispert S, Kurz A, Waibel S, et al. The modulation of amyotrophic lateral sclerosis risk by ataxin-2 intermediate polyglutamine expansions is a specific effect. Neurobiol Dis 2012;45:356-361.
41. Yamashita C, Tomiyama H, Funayama M, et al. Evaluation of polyglutamine repeats in autosomal dominant Parkinson's disease. Neurobiol Aging 2014;35:1779.e17-1779.e21.

42. Nielsen TT, Svenstrup K, Budtz-Jorgensen E, et al. ATXN2 with intermediate-length CAG/CAA repeats does not seem to be a risk factor in hereditary spastic paraplegia. J Neurol Sci 2012;321: 100102.

43. Lu CS, Wu Chou YH, Kuo PC, et al. The parkinsonian phenotype of spinocerebellar ataxia type 2. Arch Neurol 2004;61:35-38.

44. Shan DE, Soong BW, Sun CM, et al. Spinocerebellar ataxia type 2 presenting as familial levodopa-responsive parkinsonism. Ann Neu- rol 2001;50:812-815.

45. Huynh DP, Del Bigio MR, Ho DH, Pulst SM. Expression of ataxin-2 in brains from normal individuals and patients with Alzheimer's dis- ease and spinocerebellar ataxia 2. Ann Neurol 1999;45:232-241.

46. Carmo-Silva S, Nobrega C, Pereira de Almeida L, Cavadas C. Unraveling the role of ataxin-2 in metabolism. Trends Endocrinol Metab 2017;28:309-318.

47. Teixeira PF, Cerca F, Santos SD, Saraiva MJ. Endoplasmic reticulum stress associated with extracellular aggregates. Evidence from transthyretin deposition in familial amyloid polyneuropathy. J Biol Chem 2006;281:21998-22003.

48. Haynes CM, Titus EA, Cooper AA. Degradation of misfolded pro- teins prevents ER-derived oxidative stress and cell death. Mol Cell 2004;15:767-776.

49. Blokhuis AM, Groen EJ, Koppers M, et al. Protein aggregation in amyotrophic lateral sclerosis. Acta Neuropathol 2013;125:777-794.

50. Ciura S, Sellier C, Campanari ML, et al. The most prevalent genetic cause of ALS-FTD, C9orf72 synergizes the toxicity of ATXN2 intermediate polyglutamine repeats through the autophagy pathway. Autophagy 2016;12:1406-1408. 